\title{
Влияние добавок кремния на свойства монокристаллов германия для инфракрасной оптики
}

\author{
(C) А.Ф. Шиманский ${ }^{1}$, Т.О. Павлюк ${ }^{2}$, С.А. Копыткова ${ }^{2}$, Р.А. Филатов ${ }^{1}$, А.Н. Городищева ${ }^{3}$ \\ ${ }^{1}$ Сибирский фредеральный университет, \\ 660047 Красноярск, Россия \\ ${ }^{2}$ Акционерное общество „Германий“, \\ 660027 Красноярск, Россия \\ ${ }^{3}$ Сибирский государственный аэрокосмический университет им. академика М.Ф. Решетнева, \\ 660037 Красноярск, Россия \\ E-mail: shimanaf@mail.ru
}

(Получена 13 марта 2017 г. Принята к печати 15 марта 2017 г.)

Выращены однородные монокристаллы твердых растворов $\mathrm{Ge}-\mathrm{Si}$ с содержанием кремния от 0.2 до 0.8 ат\%, легированные сурьмой. Методом инфракрасной фурье-спектроскопии в интервале температуры от 25 до $60^{\circ} \mathrm{C}$ на длине волны 10.6 мкм исследовано оптическое поглощение монокристаллов с удельным электрическим сопротивлением 2-3Ом·см. Установлено, что при введении кремния в Ge возрастает температурная стабильность оптических свойств кристаллов.

DOI: 10.21883/FTP.2018.02.45456.8529

\section{1. Введение}

Первые публикации по оптическим свойствам германия появились в 1970-е годы [1,2]. В патенте [3] предлагается использование кристаллов германия $n$-типа проводимости в качестве линз для инфракрасного диапазона длин волн. В настоящее время германий, легированный $\mathrm{Sb}$, является основным материалом, служащим оптической средой в разнообразных приборах в инфракрасной области спектра от 3 до 12 мкм [4,5]. Данный материал с удельным электрическим сопротивлением от 3 до 40 Ом · см и плотностью дислокаций $<10^{4} \mathrm{~cm}^{-2}$ обладает высокой прозрачностью при комнатной температуре, которая вблизи края полосы пропускания на длине волны 10.6 мкм изменяется в интервале от 46.1 до $45.2 \%$ в зависимости от величины удельного сопротивления кристалла. Соответствующие значения коэффициента поглощения $\alpha$ составляют от 0.015 до $0.030 \mathrm{~cm}^{-1}[1,2,6]$.

В работах [3,7] отмечается, что основным недостатком оптического германия является снижение пропускания в области прозрачности и возрастание коэффициента поглощения при повышении температуры. Рост поглощения становится заметным при температуре выше $45^{\circ} \mathrm{C}$. Например, для кристаллов с удельным сопротивление 3 Ом · см, характеризующихся максимальной температурной стабильностью, при повышении температуры от комнатной до $77^{\circ} \mathrm{C}$ коэффициент поглощения возрастает от 0.015 до $0.1 \mathrm{~cm}^{-1}$. При $60^{\circ} \mathrm{C}$ значение $\alpha$ составляет $\sim 0.065 \mathrm{~cm}^{-1}$, что отвечает данным, приведенным в современных источниках $[8,9]$.

Снижение прозрачности обусловлено физической природой германия и определяется малой шириной запрещенной зоны (0.72 эВ при абсолютном нуле температуры); в области прозрачности Ge для инфракрасного излучения преобладает поглощение на свободных тер- могенерированных носителях заряда, преимущественно на дырках $[3,10,11]$.

Одним из направлений повышения температурной стабильности эксплуатационных характеристик инфракрасной оптики на основе германия является увеличение ширины запрещенной зоны полупроводникового материала путем введения в Ge изовалентного элемента кремния. Ширина запрещенной зоны в системе $\mathrm{Ge}-\mathrm{Si}$ возрастает от 0.72 до 1.2 эВ при абсолютном нуле [12].

Известно, что монокристаллы твердых растворов $\mathrm{Ge}-\mathrm{Si}$ используются в микро- и оптоэлектронике, они применяются для изготовления солнечных элементов, фотодетекторов, рентгеновских и нейтронных монохроматоров, $\gamma$-детекторов, терморезисторов и высокотемпературных термоэлектрических генераторов. Вместе с тем данные о влиянии добавок $\mathrm{Si}$ на температурное поведение оптических свойств германия ограничены и носят преимущественно качественный характер [12,13].

Для практического применения необходимы кристаллы $\mathrm{Ge}-\mathrm{Si}$ с низкой плотностью дислокаций, выращивание которых является сложной задачей, поскольку компоненты значительно различаются по параметру решетки и температуре плавления. Способ повышения кристаллического качества монокристаллов твердых растворов системы германий-кремний предложен в работе [14]. Решение проблемы заключается в использовании постепенной подпитки расплава германия кремнием путем растворения стержней $\mathrm{Si}$, размещенных в специальном держателе параллельно оси выращивания. Растворение стержней начинается лишь после затравливания и выхода кристалла германия на диаметр при приведении их в соприкосновение с поверхностью расплава.

В работе [15] для повышения температурной стабильности свойств оптических монокристаллов германия нами предложено вводить в исходную загрузку, наряду с 
основной легирующей добавкой — сурьмой, также кремний и дополнительно теллур. Максимальный эффект от легирования наблюдается в кристаллах с удельным электрическим сопротивлением 3 Ом · см. В случае тройного легирования для кристаллов, содержащих кремний в количестве от 0.05 до 0.15 ат\%, с концентрацией теллура $\sim 5 \cdot 10^{13} \mathrm{~cm}^{-3}$, значения коэффициента оптического поглощения на длине волны 10.6 мкм при $60^{\circ} \mathrm{C}$ составляют от 0.060 до $0.058 \mathrm{~cm}^{-1}$, т.е. ниже соответствующего значения для монокристаллов, легированных только сурьмой $\left(0.065 \mathrm{~cm}^{-1}\right)$.

Границы интервала концентраций кремния и теллура обусловлены тем, что при меньших значениях положительный эффект отсутствует, а при концентрациях, превышающих указанные пределы, ухудшается кристаллическое качество монокристаллов как следствие большого различия ионных радиусов германия и легирующих компонентов, в большей степени - теллура. Кроме того, высокие летучесть и токсичность теллура создают дополнительные технологические трудности выращивания монокристаллов. В связи с этим настоящая работа направлена на повышение температурной стабильности оптических свойств кристаллов путем увеличения содержания в них кремния с сохранением монокристалличности за счет исключения теллура из числа легирующих добавок.

Цель работы - исследование влияния добавок кремния в количестве $>0.15$ ат\% на оптические свойства монокристаллов германия, легированных сурьмой.

\section{2. Методика эксперимента}

Монокристаллы твердых растворов $\mathrm{Ge}-\mathrm{Si}$ выращивали методом Чохральского из кварцевого тигля на установке типа „Редмет“ в атмосфере аргона при избыточном давлении 0.02 МПа. Масса загрузки зонноочищенного германия марки ГПЗ-1 (германий поликристаллический зонноочищенный) составляла 4 кг, диаметр выращенных слитков был 40-60 мм. Кристаллографическое направление выращивания было [111], скорость вращения тигля составляла 4-6 об/мин, скорости вращения и подъема затравки -20 об/мин и $0.1-0.5$ мм/мин соответственно. Основную легирующую добавку сурьму вводили в загрузку в форме лигатуры $\mathrm{Ge}-\mathrm{Sb}$. При введении кремния в исходную загрузку в необходимом количестве, рассчитанном исходя из заданной его концентрации в кристалле $(>0.15 \mathrm{aT} \%)$ и значения эффективного коэффициента распределения [16], нарушалась монокристалличность получаемого материала. Повышение структурного качества кристаллов достигали с использованием способа постепенного насыщения расплава путем введения кремния по способу, предложенному в [14].

Из выращенных кристаллов изготавливали полированные образцы в форме плоскопараллельных пластин толщиной 1.0 см для определения оптических характеристик. Спектр оптического пропускания регистрировали в диапазоне длин волн от 2.5 до 16.6 мкм (волновые числа 4000-600 см ${ }^{-1}$ ) с помощью инфракрасного (ИК) фурье-спектрометра SPECTRUM BXII. Точность определения оптического пропускания составляла $\pm 0.1 \%$. Для измерений при повышении температуры до $60^{\circ} \mathrm{C}$ использовали нагревательную приставку, обеспечивающую стабильное термостатирование образца с точностью $\pm 0.1^{\circ} \mathrm{C}$.

По полученным спектрам определяли оптическое пропускание $T$ на длине волны 10.6 мкм и рассчитывали коэффициент поглощения по формуле

$$
\alpha=-\frac{1}{t} \ln \left[\left(\frac{(1-r)^{4}}{4 r^{4} T^{2}}+\frac{1}{r^{2}}\right)^{1 / 2}-\frac{(1-r)^{2}}{2 r^{2} T}\right],
$$

где $t$ - толщина исследуемого образца, $\alpha-$ коэффициент поглощения, $r-$ коэффициент отражения.

\section{3. Результаты и обсуждение}

Выращены однородные монокристаллы твердых растворов $\mathrm{Ge}-\mathrm{Si}$ с содержанием кремния от 0.2 до $0.8 \mathrm{aT} \%$, легированные сурьмой до удельного электрического сопротивления 2-3Ом · см. Фотография кристалла с содержанием Si $0.6-0.8$ ат\% представлена на рис. 1.

Плотность дислокаций в экспериментальных кристаллах в интервале концентрации $\mathrm{Si}$ от 0.2 до 0.8 ат\% составляет $\sim 5 \cdot 10^{3} \mathrm{~cm}^{-2}$. С увеличением доли кремния до 1.5 ат\% плотность дислокаций резко возрастает. В слитках с содержанием кремния от 2.0 до 2.5 ат\% фор-

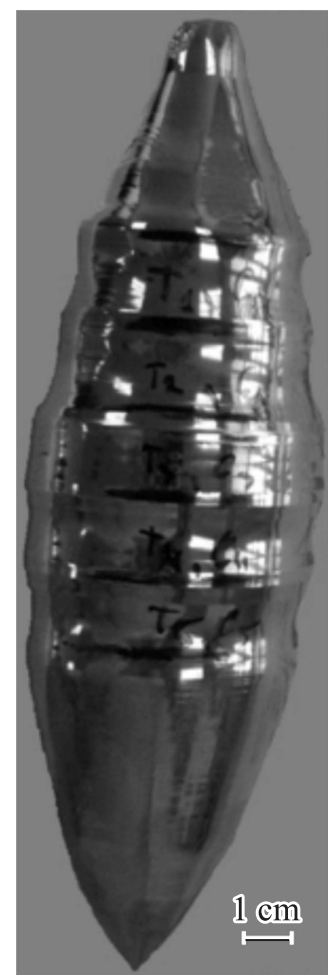

Рис. 1. Кристалл $\mathrm{Ge}-\mathrm{Si}$ с содержанием $0.6-0.8 \mathrm{aT} \% \mathrm{Si}$. 
мируется секторная структура и микросегрегационная неоднородность, как показано на рис. 2, $a$.

При увеличении концентрации кремния до 3.0 ат\% появляются некогерентные гетерогенные включения и нарушается монокристалличность слитка (рис. 2, b).

Из однородных монокристаллов с концентрацией кремния от 0.2 до 0.8 ат\% изготавливали полированные образцы для измерения оптического пропускания.

Результаты исследования оптических характеристик экспериментальных образцов в исследуемом интервале концентраций кремния при комнатной температуре и нагревании до $60^{\circ} \mathrm{C}$ представлены на рис. 3 и в таблице.

На рис. 3 приведены спектры пропускания кристалла $\mathrm{Ge}-\mathrm{Si}$, легированного сурьмой, с содержанием кремния в количестве 0.6 ат\% и удельным электрическим сопротивлением 3 Ом · см.

Установлено, что при волновом числе $943 \mathrm{~cm}^{-1}$, которое соответствует длине волны 10.6 мкм, при комнатной температуре оптическое пропускание эксперимен-

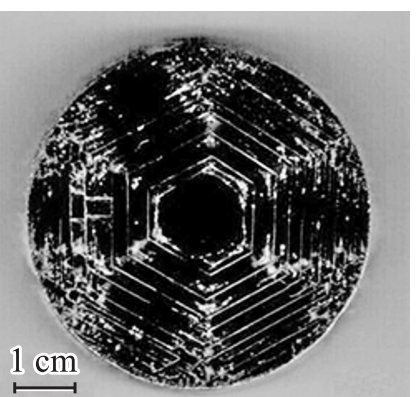

Рис. 2. Микроструктура слитков с концентрацией кремния 2.5 (a) и $3.0 \mathrm{aT} \%, \times 450(b)$.

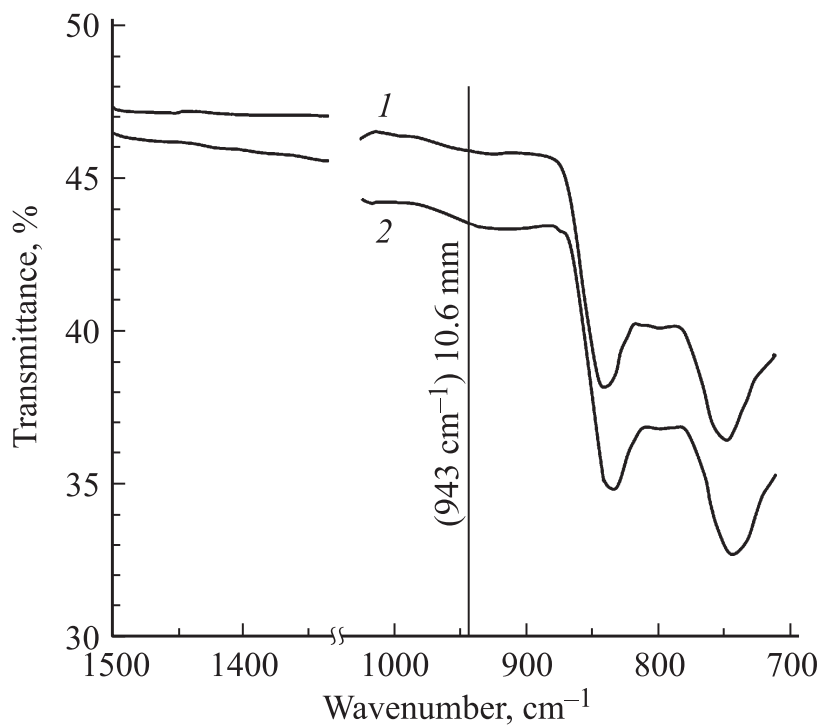

Pис. 3. ИК спектры пропускания кристалла $\mathrm{Ge}-\mathrm{Si}$, легированного сурьмой, с содержанием кремния 0.6 ат\% и удельным электрическим сопротивлением 3 Ом · см в интервале волновых чисел от 1500 до $700 \mathrm{~cm}^{-1}$ при 25 (1) и $60^{\circ} \mathrm{C}(2)$.
Оптические характеристики монокристаллов $\mathrm{Ge}-\mathrm{Si}$ на длине волны 10.6 мкм

\begin{tabular}{c|c|c|c|c|c}
\hline \multirow{2}{*}{$\begin{array}{c}\text { Концентра- } \\
\text { ция Si, ат.\% }\end{array}$} & $\begin{array}{c}\text { Удельное } \\
\text { сопротивление, } \\
\text { Ом · см }\end{array}$ & \multicolumn{2}{|c|}{$25^{\circ} \mathrm{C}$} & \multicolumn{2}{|c}{$60^{\circ} \mathrm{C}$} \\
\cline { 3 - 6 } & & $T, \%$ & $\alpha, \mathrm{cm}^{-1}$ & $T, \%$ & $\alpha, \mathrm{cm}^{-1}$ \\
\hline 0.0 & 3.0 & 46.10 & 0.015 & 43.10 & 0.065 \\
0.2 & 3.0 & 46.10 & 0.015 & 43.35 & 0.060 \\
0.3 & 3.0 & 46.20 & 0.013 & 43.50 & 0.058 \\
0.8 & 2.0 & 45.60 & 0.024 & 43.80 & 0.053 \\
0.6 & 2.0 & 45.40 & 0.027 & 43.70 & 0.054 \\
0.6 & 3.0 & 46.20 & 0.013 & 43.55 & 0.057
\end{tabular}

тального кристалла составляет 46.20\% (рис. 3). Данному значению $T$ отвечает коэффициент поглощения $0.013 \mathrm{~cm}^{-1}$. При возрастании температуры от комнатной до $60^{\circ} \mathrm{C}$ пропускание снижается до $43.55 \%$ (рис. 3 ), соответственно коэффициент поглощения возрастает до $0.057 \mathrm{~cm}^{-1}$. Приведенное значение $\alpha$ при $60^{\circ} \mathrm{C}$ на $0.008 \mathrm{~cm}^{-1}$ меньше коэффициента поглощения кристалла с удельным электрическим сопротивлением 3 Ом · см, не содержащего добавки кремния.

Для образцов с удельным сопротивлением 2Ом см при содержании кремния 0.6 ат\% коэффициент поглощения при высокой температуре снижается еще больше, до 0.054 (см. таблицу). Вместе с тем при уменьшении удельного сопротивления с 3 до 2 Ом · см наблюдается уменьшение оптического пропускания кристалла при комнатной температуре от 46.20 до $45.4 \%$, что соответствует данным, приведенным в работах $[1,6,8,9]$, и является, вероятно, следствием роста примесного поглощения, вызванного возрастанием концентрации сурьмы. Минимальный измеренный коэффициент поглощения отвечает верхней границе исследуемого интервала концентраций кремния. Для образца с удельным электрическим сопротивлением 2 Ом · см, содержащего $0.8 \mathrm{aT} \% \mathrm{Si}$, значение $\alpha$ составляет $0.053 \mathrm{~cm}^{-1}$.

\section{4. Заключение}

В монокристаллах германия, легированных сурьмой, с удельным электрическим сопротивлением 3 Ом · см при повышении температуры от комнатной до $60^{\circ} \mathrm{C}$ коэффициент поглощения на длине волны 10.6 мкм возрастает от 0.015 до $0.065 \mathrm{~cm}^{-1}$. Экспериментально доказано, что введение кремния повышает температурную стабильность оптических характеристик кристаллов. При увеличении концентрации кремния до $0.6 \%$ коэффициент оптического поглощения при $60^{\circ} \mathrm{C}$ снижается от 0.065 до $0.057 \mathrm{~cm}^{-1}$.

Исследование выполнено при финансовой поддержке Российского фонда фундаментальных исследований, Правительства Красноярского края, Красноярского краевого фонда поддержки научной и научно-технической деятельности в рамках научного проекта № 16-43-240719. 


\section{Список литературы}

[1] E.D. Capron, O.L. Brill. Appl. Optics, 12, 569 (1973).

[2] P.J. Bishop, A.F. Gibson. Appl. Optics, 12, 2549 (1973).

[3] D.J. Pedder. Patent WO 1987000297 A1. Plessey overseas Limited [GB/GB]; application number: PCT/GB86/00389; filling date: 04.07.1986; publication date: 15.01.1987.

[4] L. Cor Claeys, E. Simoen. Germanium-based technologies: from materials to devices (Oxford, Elsevier, 2007) p. 18.

[5] B. Depuydt, A. Theuwis, I. Romandic. Mater. Sci. Semicond. Processing, 9 (4-5), 437 (2006).

[6] И.М. Несмелова, Н.И. Астафьев. Прикладная физика, № 5, 33 (2007).

[7] K.A. Osmer, C.J. Pruszynski, J. Richter. Proc. SPIE, 1112, 83 (1989).

[8] Umicore Germanium Optics Leading the Way in Infrared Optics. http://eom.umicore.com/en/materials/library/brochures AndMarketingMaterial/show_GermaniumOpticsBrochure.pdf

[9] http://www.tydexoptics.com/materials1/for_transmission_optics/germanium/

[10] Р. Бьюб. Фотопроводимость твердых тел (М., Изд-во иностр. лит., 1962).

[11] W. Kaiser, R.J. Collins, H.Y. Fan. Phys. Rev., 91 (6), 1380 (1954).

[12] G. Kissinger, S. Pizzini. Silicon, Germanium, and their alloys: growth, defects, impurities and nanocrystals (Crc Press Llc, 2015).

[13] N.V. Postikova, A.Ya. Gubenko. RF Patent № 1461046 (1996).

[14] N.V. Abrosimov, S.N. Rossolenko, W. Thieme, A. Gerhardt, W. Schröder. J. Cryst. Growth., 174, 182 (1997).

[15] О.И. Подкопаев, А.Ф. Шиманский., С.А. Копыткова, Р.А. Филатов, Н.О. Голубовская. ФТП, 10, 1309 (2016). [O.I. Podkopaev, A.F. Shimanskiy, S.A. Kopytkova, R.A. Filatov, N.O. Golubovskaya. Semiconductors, 50, 1287 (2016)].

[16] I. Yonenaga, A. Matsu, S. Tozawa, K. Sumino, T. Fukuda. J. Cryst. Growth, 154, 275 (1995).

Редактор Л.В. Шаронова

\section{The effect of silicon additive on the properties of germanium single crystals for infrared optics}

\author{
A.F. Shimanskii ${ }^{1}$, T.O. Pavlyuk ${ }^{2}$, S.A. Kopytkova ${ }^{2}$, \\ R.A. Filatov ${ }^{1}$, A.N. Gorodishcheva ${ }^{3}$ \\ ${ }^{1}$ Siberian Federal University, \\ 660047 Krasnoyarsk, Russia \\ 2 Joint-stock company „Germanium“, \\ 660027 Krasnoyarsk, Russia \\ ${ }^{3}$ Reshetnev Siberian State Aerospace University, \\ 660037 Krasnoyarsk, Russia
}

Abstract Homogeneous Sb-doped single crystals of $\mathrm{Ge}-\mathrm{Si}$ solid solutions were grown with silicon content from 0.2 to 0.8 at.\%. The optical absorption of single crystals with resistivity $2-3 \Omega \cdot \mathrm{cm}$ was studied by the infrared Fourier spectroscopy at the $10.6 \mu \mathrm{m}$ wavelength and in the temperature range from 25 to $60^{\circ} \mathrm{C}$. It was established that the introduction of silicon additives into antimonydoped germanium improves the temperature stability of optical properties of the crystals. 